\title{
EL VALOR DISCURSIVO DE LOS REFRANES ${ }^{1}$
}

\author{
Inmaculada Penadés Martínez \\ Universidad de Alcalá \\ inmaculada.penades@uah.es
}

\begin{abstract}
Resumen
El artículo muestra la necesidad de analizar los refranes desde una perspectiva textual. Por otra parte, se examina la frecuencia de uso de los refranes en distintos corpus orales del español. Se aportan explicaciones sociológicas sobre su baja frecuencia de uso. Y, finalmente, se realiza un análisis textual de los refranes que aparecen en un corpus oral.
\end{abstract}

PALABRAS CLAVE: análisis del discurso, español, refranes, frecuencia de uso de los refranes, corpus orales, análisis sociológico de los refranes.

\begin{abstract}
This article focuses on the need to analyse proverbs from a discourse point of view considering the nature of its statements within a text. On the other hand, it has proved proverbs are barely used in a group of corpora gathering Oral Spanish samples. Furthermore, sociological explanations are provided regarding its low frequency of use. Finally, the article presents the discourse analyse for six proverbs in order to show the possibilities of this kind of studies.

KEY WORDS: discourse analysis, Spanish, proverbs, frequency of use of proverbs, spoken corpora, sociological analysis of proverbs.
\end{abstract}

1. De manera análoga a lo que ocurre con otras muchas nociones lingüísticas, la concepción que se tiene del refrán no es la misma para todos los investigadores. Así, acudiendo a estudiosos de distintas épocas, formaciones y adscripciones metodológicas, observamos que Casares (1969 [1950]: 192), por ejemplo, lo define como

frase completa e independiente, que en sentido directo o alegórico, y por lo general en forma sentenciosa y elíptica, expresa un pensamiento --hecho de experiencia, enseñanza, admonición, etc.-, a manera de juicio, en el que se relacionan por lo menos dos ideas.

l Este artículo se enmarca en el proyecto de I+D "Diccionario de locuciones para la enseñanza del español" (BFF2003-05486), financiado por el Ministerio de Ciencia y Tecnología. Por otra parte, corresponde a la conferencia que, bajo el mismo título, impartí en la Universidad de Alicante en el seno de las VIII Jornadas de Estudios de Lingǘstica. Análisis del discurso. Este texto reproduce, prácticamente de manera íntegra, el de la conferencia, sin más cambios que los exigidos por el distinto tipo de discurso, por eso no figura ningún aparato crítico en notas a pie de página, pues éstas sólo se han utilizado para añadir alguna información adicional aclaratoria. Desde aquí quiero expresar públicamente mi más profundo agradecimiento a los profesores de las áreas de Lengua Española y de Lingüistica General por su invitación a participar en las jornadas y por su cálida acogida. 
Por su parte, el hispanista Combet (1971: 58) considera que

Le refrán serait, en définitive, une phrase indépendante anonyme et notoire qui, sous une forme eliptique, directe ou de préférence figurée, exprime poétiquement un enseignement ou un avis d'ordre moral ou practique.

Más recientemente, Sevilla Muñoz (1993: 15) proporciona no tanto una definición de refrán como la siguiente relación de características: estructura bimembre, idiomaticidad, elementos mnemotécnicos, carácter y uso popular, e incluso festivo y jocoso; sin bien en la actualidad considera que el refrán es

una paremia popular que se caracteriza por una temática genérica, un sentido idiomático, elementos mnemotécnicos, un alcance universal y una morfosintaxis a veces arcaica (Almela Pérez y Sevilla Muñoz 2000: 16).

Conviene precisar ahora que una paremia, para Almela Pérez y Sevilla Muñoz (2000: 12), es un enunciado. Por último, Corpas Pastor (1996: 148-150) recurre asimismo al procedimiento de la caracterización, pues asigna a los refranes las características de las paremias, en general: lexicalización, autonomía sintáctica y textual, valor de verdad general y carácter anónimo, más las adicionales y específicas de significado metafórico, particularidades fónicas, anomalías sintácticas, o estructuras sintácticas particulares, carácter tradicional y propósito didáctico o dogmático.

Sea cual sea la caracterización que podamos preferir como punto de partida, todas ellas inciden, de una manera u otra, en la naturaleza oracional del refrán. Ahora bien, como la oración no es la unidad superior de análisis lingüístico ni, generalmente, aparece aislada en la secuencia hablada, sino que, más bien, se incardina en un texto, tendremos que deducir, consecuentemente, que la perspectiva natural para estudiar un refrán es la que proporciona su inclusión en un texto o en un discurso.

Paradójicamente, sin embargo, el refrán se ha analizado con mayor detalle en cuanto a sus características fonéticas: rima y distribución acentual: Año de nieves, año de bienes, morfológicas: carácter intemporal de los tiempos verbales: Del árbol caido todos hacen leña, léxicas: aparición de dialectalismos, latinismos o arcaísmos como sayo en Cada uno puede hacer de su capa un sayo o en Hasta el cuarenta de mayo no te quites el sayo, sintácticas: uso del relativo de generalización: Quien canta, su mal espanta, y retóricas, entendiendo por tales la existencia de metáforas, metonimias o comparaciones: De tal palo tal astilla ${ }^{2}$. En grado mucho menor se ha estudiado el refrán en función de su valor discursivo. Dos circunstancias pueden haber provocado esta situación: por una parte, el retraso en la constitución de la Lingüística del texto o del Análisis del discurso como disciplinas lingüísticas en relación con otras ciencias de la Lingüística de más larga tradición y desarrollo, frente al interés no ya centenario, sino milenario, que han despertado las paremias, en general, sobre todo en cuanto a su recolección.

La segunda circunstancia se refiere a la propia situación del análisis de las paremias dentro del ámbito de la Lingüística, situación que no es la mejor ni la más deseable. Tal 
vez la consideración de estas unidades como no pertenecientes al sistema de la lengua ha ido excluyendo su estudio desde una perspectiva estrictamente lingüística a favor de aproximaciones filológicas, literarias, antropológicas o culturales en sentido amplio. Y muy posiblemente la concepción de Coseriu acerca de los refranes sea el punto de partida de esta situación. No creo que esté ahora de más recordarla. En el intento de determinar lo que puede ser o no objeto de análisis estructural, Coseriu (1966: 194-197) distingue entre técnica del discurso y discurso repetido. Este último comprende todo lo que está tradicionalmente fijado como expresión, frase o locución, con la salvedad de que sus elementos constitutivos no se pueden reemplazar ni combinar de nuevo según las reglas de la lengua. El primer grupo de unidades que incluye en el discurso repetido son las frases metafóricas, los proverbios, los dichos, las sentencias, los wellerismos y los refranes. Coseriu tiene muy clara su caracterización: sólo son conmutables en el plano de las oraciones y de los textos por otras oraciones y por textos enteros, su interpretación sólo es posible en el plano de las oraciones y de los textos y son, en realidad, textos y fragmentos de textos que, en el fondo, constituyen documentos literarios, una forma de la literatura englobada en la tradición lingüística y transmitida por la tradición lingüística. En este sentido, llega a decir explícitamente que los refranes son una forma de la literatura popular española. Por ello, para el gran lingüista de Tübingen, su estudio pertenece, en rigor, a las ciencias literarias y a la filología. La lingüística no puede intervenir más que en calidad de ciencia auxiliar: para establecer la etimología de los elementos de estas unidades textuales. En consecuencia, para Coseriu es un error atribuir proverbios y refranes a la lexicología y considerarlos lexemas o léxico. Pero Coseriu no acierta del todo con esta concepción. Que los refranes no formen parte de la lexicología o de la lexemática, que los refranes no sean elementos léxicos o que los refranes no puedan ser objeto de un análisis estructural como las unidades léxicas incluidas en los campos semánticos, no significa que no sean unidades lingüísticas ni que su estudio no tenga una ubicación dentro de la lingüística (la lingüística no es sólo lexemática o lexicología). A pesar de que Coseriu fue uno de los pioneros en el establecimiento de la lingüística del texto, curiosamente no fue capaz de percibir que en ese nivel de análisis es donde tiene sentido ubicar los refranes, y eso que les reconoce su carácter textual, ni vio tampoco que a través de las metodologías que se han desarrollado para abordar el nivel textual es como hay que analizarlos.

La influencia de la obra de Coseriu en la lingüística hispánica ha tenido un gran peso, $\mathrm{y}$, desde esta perspectiva, se comprende que, repasando los índices de los 14 números de la revista Paremia publicados desde 1993 hasta ahora, la mayoría de contribuciones allí incluidas se interesen por analizar los refranes, como paremia más representativa, en obras literarias de distintos períodos y autores o por examinarlos en tanto que modos de expresión para hablar de conceptos como el tiempo, la religión, la mujer o el vino; y sumadas a estas líneas de investigación, figuran las que siendo de orden lingüístico, pero más bien aplicado, se ocupan de los refranes desde una perspectiva contrastiva, traductológica, didáctica o lexicográfica, pero no específica ni prioritariamente desde una perspectiva textual.

Si lo que acabo de decir se entiende como un reproche, que conste que no va dirigido a los paremiólogos, sino a los lingüistas o a los fraseólogos, que todavía no hemos abordado suficientemente estas unidades fraseológicas desde un enfoque específicamente lingüístico. Dejo de lado los estudios que he mencionado anteriormente centrados en las características fonéticas, morfológicas, sintácticas o léxicas de los refranes, que los abordan lingüística- 
mente, pero, en realidad, ninguna de ellas por separado da cuenta de la verdadera naturaleza de un refrán y todas juntas, con exclusión de las características textuales, no llegan tampoco a establecerla.

2. Claro está que siempre se pueden citar honrosas excepciones a esto que estoy comentando, es el caso de los trabajos de Conca (1987), Almela Pérez y Sevilla Muñoz (2000), Laborda Gil (2004), o Manero Richard (2005), por ejemplo. El más claro y el que se anticipa a todos es el de Conca. Hace ya veinte años esta autora definió el refrán como

un text força breu, potser un dels més condensants de la nostra enciclopèdia cultural, que se situa en el marc de la intertextualitat, és portador de producció de sentit amb coherència sintàctica, semàntica i pragmàtica, i forma un text íntegre que és immediatament reconegut pels parlants que pertanyen a una mateixa cultura (Conca 1987: 15).

Desde esta concepción textual del refrán, en su obra los analiza como actos de habla: Qui la fa la paga tendrá una determinada fuerza ilocutiva, según el contexto de uso; como textos que en sí mismos se caracterizan por presentar elementos de cohesión textual como la anáfora: No deixes les sendes velles per novelles; por la presencia / ausencia de definidor: La por guarda la vinya / Cel a borreguets, aigua a canterets; por el valor genérico de los tiempos: Qui no sap fer la feina, no sap manar-la, al presente se añade el relativo de generalización, y por la aparición de conectivos: Si la Candelària plora l'hivern està fora. Y, por último, en relación con la estructura profunda de los textos en que aparecen, así como en relación con sus funciones semióticas, Conca señala que el refrán es un texto codificado e intertextualizado en cualquier tipo de macrotextos, cuya misión puede ser la de resumen, glosa, leit-motiv, tema, cita irónica, etc., etc.

La aportación de Almela Pérez y Sevilla Muñoz se presenta como una propuesta de análisis lingüístico de las paremias con vistas a la elaboración de colecciones de estas unidades. El análisis en cuestión debería abarcar los niveles fonémico, morfémico, lexémico, sintáctico y textual. En cuanto a este último, estos autores consideran que el tratamiento lexicográfico de cada paremia debería mostrar el protagonista, el tema, la designación, las relaciones de hiperonimia, sinonimia y antonimia que mantiene con otras paremias, las funciones comunicativas que cumple, la deíxis y los conectores textuales. Tomando un ejemplo, en el refrán Aunque la mona se vista de seda, mona se queda, el protagonista es un animal; el tema, aquello que se dice del protagonista, son las apariencias y la belleza; la designación corresponde a la explicación o paráfrasis del refrán, en el caso que nos ocupa: "Aunque se intente, no se consigue ocultar la realidad personal"; el refrán en cuestión es hipónimo de otro: Las apariencias engañan, sinónimo de otros: Te conozco, bacalao, aunque vengas 'disfrazao'-El hábito no hace al monje, y antónimo de Compón el sapillo, parecerá bonillo ${ }^{3}$. Por su parte, los refranes pueden cumplir las funciones comunicativas de constatación: Los niños y los locos dicen las verdades, elogio: De buena casa, buena brasa, vituperio: Dime de qué presumes y te diré de qué careces, persuasión: A mal tiempo, buena cara, y disuasión: A boda ni bautizo no vayas sin ser llamado. En relación con la deíxis textual, Almela Pérez

3 Téngase en cuenta que, según Campos y Barella (1996: 316), este refrán significa que 'La ropa y el arreglo personal disimulan la fealdad'. 
y Sevilla Muñoz consideran que para cada refrán habría que identificar posibles alusiones al emisor y al receptor, al espacio, al tiempo y al referente personal o general. Por último, en el apartado dedicado a los conectores textuales, habría que señalar los marcadores de cita: "Como dice el refrán: Aunque la mona se vista de seda, mona se queda", de argumentación: "Porque ya se sabe: Aunque la mona se vista de seda, mona se queda", y de deducción que puedan acompañar al refrán.

Justamente, el trabajo de Laborda Gil (2004) constituye una aplicación de esta propuesta al análisis de las paremias que decoran las paredes del patio de la antigua Casa de la Caritat de Barcelona.

En la última referencia bibliográfica que he citado sobre el estudio del valor discursivo de los refranes, la de Manero Richard (2005), estas unidades fraseológicas son analizadas como unidades polifónicas, dado que el locutor no coincide con el autor. Este último se identifica con una conciencia lingüística colectiva, con la comunidad lingüística, más en concreto con la sabiduría popular, origen de los refranes, la cual se refleja lingüísticamente en fórmulas introductorias del tipo "Como dice el refrán...". Desde esta perspectiva el locutor del refrán, el sujeto hablante que lo enuncia, no está obligado a manifestar su adhesión a la carga cultural o ideológica de la paremia emitida, pero sí tiene la responsabilidad pragmática de adecuar con éxito la situación-tipo establecida por la paremia al contexto del aquí y ahora de la enunciación. Junto a estas observaciones que subrayan la polifonía en el refrán, Manero Richard analiza sus coincidencias y divergencias con los tipos de citas y, partiendo de que el refrán es una reproducción de dicto, como las citas, esboza sus diferencias en relación con este último tipo de unidad fraseológica, diferencias que surgen de la consideración del refrán

como repetición de una enunciación-eco, como texto tradicional y extraordinariamente expresivo, fijado en el nivel individual del lenguaje, cuya fuente es popular, colectiva y generalmente anónima (Manero Richard 2005: 113).

3. Subrayado el valor textual de los refranes y constatada la necesidad de su análisis, parece oportuno ofrecer ejemplos de las posibilidades que una investigación de este tipo ofrece, porque, realmente, los trabajos que he citado no llevan a cabo estudios sistemáticos sobre datos, con la excepción del artículo de Laborda Gil, aunque, como he mencionado, está restringido a las paremias esculpidas en unas paredes. Para ello, se impone como primera exigencia la elaboración de un pequeño corpus de refranes insertos en algún tipo de discurso. Pero esta tarea no es tan sencilla como a primera vista pudiera parecer. A pesar de que es habitual caracterizar las unidades fraseológicas como propias del registro oral coloquial, el análisis de muestras de este registro de lengua hace ver que esa afirmación no es verdadera para todas las clases y subclases de unidades fraseológicas. Ya he tenido ocasión de demostrarlo en relación con las locuciones verbales (Penadés Martínez 2004) y también lo he comprobado ahora por lo que respecta a los refranes. Tampoco en el español de algunos medios de comunicación la presencia de las paremias es especialmente significativa. No en vano los paremiólogos españoles constatan el menor uso del refrán en la sociedad actual (Sevilla y Cantera 2002: 255-263), y de ahí los intentos por determinar cuáles son los refranes que conocen, recuerdan y usan los hablantes, con la finalidad tanto de establecer la competencia pasiva y activa de estudiantes de primaria, secundaria (Díaz Pérez 1997) 
y universitarios (Tejero Robledo 1997), como de fijar lo que se ha denominado el mínimo paremiológico para el buen dominio de una lengua, como materna (Tarnovska 2005) y como extranjera (Campo Martínez 2001). Este concepto ha sido definido por Tarnovska (2005: 199) como "el número de paremias que necesariamente entra en la competencia lingüística pasiva y activa del hablante nativo", frente al máximo, entendido como el conjunto de paremias existentes en una lengua; lo que aplicado al caso del refrán, supone decir el refranero en toda su extensión (Sevilla Muñoz y Barbadillo de la Fuente 2005: 1).

En relación con el mínimo paremiológico, hay dos cuestiones que quisiera nacer notar. $1^{\text {a }) ~ E l ~ m i ́ n i m o ~ p a r e m i o l o ́ g i c o ~ f i j a d o ~ p a r a ~ d i s t i n t a s ~ l e n g u a s ~ v a r i ́ a ~ e n t r e ~ l a s ~} 300$ paremias del ruso establecidas por Permiakov y la treintena del inglés, según Mieder, pasando por 255 del español, a partir de los datos ofrecidos por Tarnovska (2005). Este número se reduce a 77 en el ámbito del español como lengua extranjera, de acuerdo con el análisis de Campo Martínez (2001). Aunque los mínimos paremiológicos para el español como lengua materna y como lengua extranjera han sido fijados por estas dos investigadoras, de manera independiente, es curioso que 70 de las 77 paremias consideradas aptas para la enseñanza del español en $\mathrm{E} / \mathrm{LE}$ formen parte de las 255 que constituyen el mínimo paremiológico de esta lengua, es decir, casi el $91 \%$ de paremias establecidas para la enseñanza del español como lengua extranjera se encuentran entre el mínimo que permitiría tener un buen dominio del español como lengua materna, lo cual avala la adecuación de los datos proporcionados por Campo Martínez en relación con la enseñanza de los refranes en E/LE ${ }^{4}$. Por otra parte, el mínimo paremiológico del español se corresponde, parcialmente también, con los resultados obtenidos en investigaciones como la de Corpas Pastor (1998), quien ha rastreado las paremias existentes en un corpus del español de la norma culta peninsular actual, el de Vox-Biblograf, constituido por diez millones de palabras. De las 79 paremias extraídas del corpus VoxBiblograf, 50 forman parte del mínimo paremiológico ofrecido por Tarnovska, eso supone una coincidencia de poco más del $63 \%$, cantidad que se incrementaría, hasta casi el $72,5 \%$, si para la comparación elimináramos del listado de Corpas paremias como Juventud divino tesoro, La religión es el opio del pueblo, La vida es sueño, No es bueno que el hombre esté solo o No sólo de pan vive el hombre, unidades fraseológicas que se incluirían en la subclase de las citas, pero no en la de los refranes. No habría que contabilizar tampoco España es diferente, Haz el amor y no la guerra o No pasarán, que entrarían más en la clase del eslogan, el lema o la consigna, y también habria que excluir del recuento unidades como haber gato encerrado y llover sobre mojado, que en el Diccionario fraseológico del español actual aparecen marcadas como locuciones verbales (Seco, Andrés y Ramos 2004: 491 y 591). Ninguna de ellas se incluye en el mínimo paremiológico de Tarnovska. En cualquier caso, todo esto muestra las dificultades existentes a la hora de establecer las clases de paremias, con vistas a cualquier tipo de análisis. Sería, pues, muy conveniente que los investigadores, al menos paremiólogos y fraseólogos, aunaran criterios con el fin de emprender investigaciones homogéneas en cuanto al objeto de estudio y la metodología utilizada.

$2^{a}$ Las investigaciones sobre el mínimo paremiológico del español se han llevado a cabo a partir de la selección por hablantes de refranes registrados en diccionarios; asimismo, a partir de encuestas que permiten obtener listas de disponibilidad paremiológica, de manera semejante a los trabajos en que se consigue la disponibilidad léxica de grupos de hablantes, 
$\mathrm{y}$, por último, mediante filtraciones hechas por hablantes sobre esos listados previos con el fin de obtener un conjunto de paremias reconocidas por éstos, es decir, el mínimo paremiológico. Ahora bien, que tengamos establecido el núcleo del refranero no significa que los hablantes hagan un uso frecuente de los refranes en situaciones reales de habla. Piénsese que los listados elaborados para llegar a ese núcleo se hacen mediante la extracción, en los diccionarios, de los refranes conocidos por hablantes y a partir de los obtenidos cuando se les pide que en un plazo de diez minutos escriban los que les vienen a la memoria. Por otra parte, el recuento del número de apariciones de un refrán en corpus como el Corpus de Referencia del Español Actual (CREA) de la Academia o en ese mundo lingüístico casi infinito que constituye la red tampoco es un dato realmente significativo respecto a su uso real. Lo que podemos registrar así es la frecuencia absoluta de un refrán en relación con el número total de palabras que, por ejemplo, conforman el CREA, pero no su frecuencia relativa. Dicho de otra manera, si un refrán equivale a una oración, sea simple o compuesta, ¿cuál es la frecuencia de aparición de un refrán en relación con el número total de oraciones existentes en un corpus? No estamos todavía en condiciones de dar respuesta a una cuestión como ésa. Sin embargo, lo que sí debe quedar claro es que la metodología de obtención del mínimo paremiológico no garantiza una elevada frecuencia de uso de los refranes en textos producidos por los hablantes. Me atrevería a afirmar que el uso real es "minimísimo" en relación con ese mínimo.

Digo esto por lo que me he encontrado al vaciar distintos corpus del español oral. En primer lugar, voy a indicar los refranes que aparecen en un corpus de materiales obtenidos de la radio y de la televisión, los primeros recogidos de Radio Nacional de España, Radio 1, durante un período de siete días de los meses de julio y agosto de 1993 y los segundos grabados de TVE 1 en un período de siete días de los meses de enero y febrero de 1992. El corpus forma parte del material recogido para el análisis del español de los medios de comunicación, dentro del proyecto DIES-RTVP (Difusión Internacional del Español por Radio, Televisión y Prensa (Moreno Fernández y Florián Reyes, 1999)). Las 80 horas de grabación transcritas contienen 750000 palabras. Pues bien, en esas 80 horas de grabación encontramos los refranes: Más vale prevenir que curar, Más vale una imagen que mil palabras, Nadie diga de esta agua no beberé, Quien roba a un ladrón tiene cien años de perdón y Si no puedes vencer a tu enemigo, únete a él.

Pero los datos que podemos encontrar en otros corpus no desdicen mucho de éstos. Son semejantes. El segundo vaciado que he hecho es el de los materiales que hasta ahora han publicado Moreno Fernández, Cestero Mancera, Molina Martos y Paredes García (2002) y (2005) sobre la lengua hablada en Alcalá de Henares, dentro del proyecto PRESEEA para el estudio de la lengua hablada de España y de América. En el volumen correspondiente a los hablantes de instrucción superior han aparecido los refranes: A la vejez viruelas, Cualquier tiempo pasado fue mejor, En casa de herrero cuchillo de palo, Nadie diga de esta agua no beberé y Nunca es tarde si la dicha es buena. Los utilizados por los hablantes de instrucción media son: Casa con dos puertas mala es de guardar, Cobra (buena) fama y échate a dormir, Del dicho al hecho hay un trecho, Nunca llueve a gusto de todos, Por San Blas la cigüeña verás, y si no la vieres año de nieves, y Tanto tienes, tanto vales. El número de horas escuchadas ha sido de unas 35 .

El tercer corpus examinado, también sobre el español hablado, ha sido el publicado hasta la actualidad sobre el español de Valencia. Gómez Molina (2001) y (2005), asimismo 
dentro del proyecto PRESEEA, ha coordinado ya dos volúmenes, los correspondientes a los hablantes de nivel sociocultural alto y medio. El resultado ha sido, de nuevo, descorazonador, porque del rastreo hecho sobre 29 horas de grabación sólo he obtenido A falta de pan, buenas son tortas, A lo hecho, pecho y Tanto tienes, tanto vales, en el volumen correspondiente al nivel alto, mientras que los refranes que aparecen en el del nivel medio son: Nunca llueve a gusto de todos, En todas partes cuecen habas, y en mi casa, a calderadas y El saber no ocupa lugar 5 .

Aunque la muestra obtenida es muy pequeña — no así el número de horas escuchadas; casi 145 en total, sumando los corpus de Alcalá de Henares, de Valencia y el de la radio y la televisión-y, en consecuencia, los datos son poco representativos, hay que hacer constar que los 22 refranes, a excepción de Por San Blas la cigüeña verás, y si no la vieres año de nieves y de Casa con dos puertas mala es de guardar, forman parte del mínimo paremiológico determinado por Tarnovska (2005). No podemos decir lo mismo respecto a su inclusión en los diccionarios de refranes. Así, Más vale una imagen que mil palabras, Por San Blas la cigüeña verás, y si no la vieres año de nieves y Si no puedes vencer a tu enemigo, únete a él no aparecen en ninguno de los cuatro diccionarios citados en la bibliografía ${ }^{6}$, a lo mejor, porque el primero y el último no son refranes en sentido estricto y el segundo puede que sea propio de determinadas zonas del español. Por su parte, El saber no ocupa lugar no forma parte de los registrados por Campos y Barella (1996) ni del diccionario de Canellada y Pallares (2001). Tal vez porque no es propiamente un refrán, sino más bien una frase proverbial. De ese modo viene marcado por Mauro Fernández (1994: 231) en su compilación lexicográfica, a pesar de que lleva por título Diccionario de refranes. De nuevo, el problema de la distinción de los tipos de paremias al que ya me he referido anteriormente.

4. Y paso ya al análisis discursivo, pero me limitaré a los seis hallados en el corpus sobre el español hablado de Valencia?. Pueden señalarse diversos aspectos.

4.1. No siempre los refranes son utilizados por el hablante en lo que podríamos denominar su forma canónica, es decir, en la forma en que son recogidos por los repertorios paremiológicos, repertorios que además no presentan una coincidencia absoluta. De los seis, tres aparecen con una forma modificada: Si no hay pan, buenas son tortas, En todos los sitios se cuecen habas y El saber ocupa lugar; en este último caso, porque el hablante se equivocó, eliminando el adverbio de negación, aunque rectificó de manera inmediata y acabó dando a entender que la equivocación no era tan grave, porque el saber sí ocupa lugar. En relación con estas variaciones formales, unas de orden sintáctico: si no hay por a falta de en el refrăn (1), presencia del determinante los frente a su ausencia en el refrán (5) y se cuecen por cuecen, en ese mismo refrán, y otras léxicas: sitios en vez de partes también en el (5), la más interesante es la que se da en este refrán al que me estoy refiriendo, dado que muestra

\footnotetext{
5 El corpus del grupo Val.Es.Co (Briz y Grupo Val.Es.Co 2002) es más reducido que los anteriores, pues el total de horas grabadas corresponde a poco más de 6 . En consecuencia, no es de extrañar que el número de refranes existentes en él sea también más escaso. De hecho, sólo se registra En todas partes cuencen habas, y en mi casa, a calderadas.

6 En concreto, Campos y Barella (1996), Canellada y Pallares (2001), Carbonell Basset (2002) y Fernández (1994).
}

$7 \quad$ En el apéndice II aparecen los refranes con sus respectivas concordancias. 
la característica de la fijación, propia de toda unidad fraseológica. Puesto que el refrán tiene una forma fija y conocida por los hablantes, no es necesario reproducirlo, citarlo de manera completa, de ahí la elisión de la segunda parte: y en mi casa, a calderadas.

4.2. Al mencionar la propuesta de análisis textual de los refranes elaborada por Almela Pérez y Sevilla Muñoz (2000), señalaba que para estos autores uno de los puntos del análisis debe referirse al examen de los conectores textuales, concretamente los marcadores de cita. Los encontramos con distintas realizaciones. El refrán (3) va precedido por el fragmento: "el esquema de valores ha sido trastocado completamente [...] por una ley de", y va seguido por el comentario: "esta ley siempre ha existido". Aparte de encontrarnos un marcador de cita, vemos aquí la denominación ley aplicada al refrán, lo que refuerza el valor de su contenido, pues siempre una ley es de obligado cumplimiento, frente a las advertencias, recomendaciones o consejos ofrecidos, en general, por los refranes. Por otra parte, el valor atemporal del contenido del refrán viene marcado por el comentario que hace el hablante después de enunciarlo: "esta ley siempre ha existido". Lo que permite ver, además, que los marcadores de cita no sólo funcionan como introductores de los refranes, sino que en ocasiones van postpuestos, aspecto este que ha sido menos considerado, al menos para el caso del español, frente a otras lenguas como el inglés y el checo, analizadas en esta cuestión por Črmák (2005). Lo mismo pasa en el refrán (4): el marcador de cita también va postpuesto, pues a la mención del refrán sigue este comentario del hablante: "nunca llueve a gusto de todos, que es lo que dicen". Habría que considerar, según esto, que los marcadores de cita muestran una deíxis, un señalamiento, bien anafórico, bien catafórico. El último ejemplo de marcador de cita lo encontramos en el refrán (5), en este caso porque va introducido por "la experiencia te indica que". De nuevo el marcador de cita subraya las características asignadas a los refranes: son la condensación de la experiencia de la gente y expresan verdades cuya validez supera el paso del tiempo.

Se puede resumir el análisis de este aspecto de los refranes señalando que los introductores textuales utilizados son nominales, caso de la palabra ley, verbos, como el de (5): indica, y expresiones polilexicales, como "que es lo que dicen". Por su parte, en cuanto a su posición, los introductores aparecen tanto antecediendo al refrán, como sirviéndole de comentario posterior. Las mismas palabras y expresiones introductorias y las posiciones antepuesta y postpuesta se dan también en otras lenguas, como demuestra para un amplio número de paremias inglesas y checas Čermák (2005).

4.3. Las propuestas de análisis textual de los refranes han insistido en la necesidad de examinar su función comunicativa, dicho de otro modo, el tipo de acto de habla al que, en principio, corresponden. Partiendo de las definiciones que los diccionarios de refranes nos proporcionan, los que he encontrado en el corpus manejado constituyen actos de habla de distintos tipos. A falta de pan, buenas son tortas y $A$ lo hecho pecho son consejos, pues del primero el diccionario de Campos y Barella (1996: 155) nos dice: "Refrán irónico que aconseja conformarse con lo que se tiene o alcanza, a falta de otra cosa mejor", mientras que sobre el segundo leemos: "Aconseja tener fortaleza para arrostrar las consecuencias de una desgracia o de un error que ya son irremediables" (Campos y Barella 1996: 278). De este modo, podemos afirmar que ambos son actos de habla ilocutivos directivos, que, en principio, pueden utilizarse para intervenir sobre la conducta del oyente. Cuestión distinta es que, 
insertos en un texto, tengan ese valor o no, como examinaremos después. Por su parte, del refrán En todas partes cuecen habas y en mi casa, a calderadas podemos considerar que es una advertencia a tenor de sus paráfrasis definitorias: "Advierte que las flaquezas humanas no son exclusivas de ningún país o lugar" y "Denota que en todas partes se hallan trabajos, y que cada uno tiene los suyos por mayores" (Campos y Barella 1996: 276). El valor intrínseco de advertencia permite, también en este caso, considerar que este refrán corresponde a un acto de habla ilocutivo directivo: una advertencia se le hace a otro, para intervenir o guiar su conducta de algún modo.

La función comunicativa de Tanto tienes, tanto vales, de Nunca llueve a gusto de todos y de El saber no ocupa lugar se deduce menos fácilmente de sus definiciones, ya que en los diccionarios sólo encontramos que el primero "Significa que el poder y la estimación entre los hombres suelen ser a proporción de la riqueza que tienen" (Campos y Barella 1996: 342 ), que, según el segundo, "La gente no siempre es de la misma opinión y es difícil que los acontecimientos agraden a todos por igual" (Carbonell Basset 2002: 280) y el tercero "da a entender que nunca estorba el saber" (Fernández 1994: 231). En cualquier caso, los tres refranes parecen ser constataciones nacidas de la sabiduría popular, de manera que pueden entenderse como aseveraciones, como actos de habla representativos, cuya verdad es asumida por el hablante.

4.4. Además de la función comunicativa asignada a cada refrán, fuera de todo contexto y situación, el refrán también tiene un valor en la macroestructura del discurso como marcador de argumento, en palabras de Almela Pérez y Sevilla Muñoz (2000), o mejor, tiene una función semiótica, tal como explica Conca (1987). Así ocurre con los que estamos examinando ${ }^{8}$.

4.4.1. A falta de pan, buenas son tortas: "Refrán irónico que aconseja conformarse con lo que se tiene o alcanza, a falta de otra cosa mejor" (Campos y Barella 1996: 155)

A: háblanos sobree tus diversiones/tus aficiones/ ¿cómo pasas el tiempo libre?

B: pues el tiempo libree/me gusta ocuparloo/ ee/ pues saliendo de acampada/ libre/mejor que guiada/ pero bueno si no hay pan buenas son tortas///(2") $\mathrm{mm} /$ pues me gusta mucho// pasear/ [...] (Gómez Molina 2001: 184-185).

El refrán $A$ falta de pan, buenas son tortas no es utilizado en el fragmento en que aparece con la fuerza ilocutiva de consejo dado por el hablante al oyente, sino que más bien tiene el valor de expresión de conformidad por parte del hablante ante una situación que no se acomoda exactamente a sus deseos. De ahí que el refrán aparezca en una oración introducida por la conjunción pero, que señala oposición a lo enunciado en la oración anterior, seguida de la interjección bueno con valor de resignación (Seco, Andrés y Ramos 1999: 744).

4.4.2. A lo hecho pecho: "Aconseja tener fortaleza para arrostrar las consecuencias de una desgracia o de un error que ya son irremediables" (Campos y Barella 1996: 278)

8 En este punto del análisis discursivo, cada refrán va precedido de su forma canónica, según la establece Tarnovska (2005), de su significado, tomado del diccionario de refranes citado, y de su concordancia, correspondiente, como se ha comentado, a la utilización del refrán en Gómez Molina (2001) y (2005). 
A: ¿sí?// hombre los japoneses están en esa línea también de disciplinaa/ y de trabajoo/ etcétera etcétera/ los chinos no tanto pero bueno/// ¿quée te hubiese gustado hacer que no hayas hecho/ o qué hubieses cambiado de tu vida?

B: creo que eso ess algoo quee/ a lo hecho pecho/// noo- no ha lugar

A: ee/ ¿piensas alguna vez en tu jubilación? [...] (Gómez Molina 2001: 205).

El refrán $A$ lo hecho pecho tampoco está utilizado con su fuerza ilocutiva propia de consejo dado al oyente. Al formar parte de una oración subordinada a un verbo de opinión, "creo que", la función comunicativa que le corresponde es también la de expresión de una creencia, sólo que esa creencia no se utiliza para aconsejar al otro, sino, más bien, para rebatir la posibilidad planteada por el interlocutor A de cambiar la vida. El hablante B considera que no tiene sentido reflexionar sobre lo que hubiera podido hacer y no ha hecho y lo manifiesta de manera contundente con ese refrán, seguido de la locución verbal no haber lugar, cuyo significado, 'no ser una cosa oportuna' (Seco, Andrés y Ramos 2004: 596), refuerza su creencia de que hay que arrostrar las consecuencias del rumbo que le ha dado a su vida. El interlocutor A capta, inmediatamente, el sentido de las palabras de B, pues de manera automática cambia de tema: "¿piensas alguna vez en tu jubilación?".

4.4.3. Tanto tienes, tanto vales: "Significa que el poder y la estimación entre los hombres suelen ser a proporción de la riqueza que tienen" (Campos y Barella 1996: 342)

A: ¿quée cambio de valores destacaría usted de aquella época a ésta?

$\mathrm{B}$ : totales/totales/ ee es decir/ la jerarquía- el esquema de valores ha sido trastocado completamente/// ee por unn consumismo atroz// ee por una ley/ dee tanto tienes tanto vales/ este- esta ley siempre ha existido/ lo que pasa que ha coexistido/ con otra serie de valores// sobre todo en las clases humildes// se primaba mucho el amor a la cultura [...] (Gómez Molina 2001: 339).

Apuntaba antes que el refrán Tanto tienes, tanto vales es un acto de habla representativo que asevera, constata una idea con cuya veracidad se compromete el hablante. Este hecho queda reforzado por el uso de la palabra ley aplicada a ese refrán. El interlocutor B está firmemente convencido de que el poder y la estimación entre los hombres suelen ser proporcionales a la riqueza que tienen, y utiliza el refrán para apoyar su argumentación de que los valores tradicionales —Dios, justicia y cultura, de acuerdo con lo que más adelante dice — han sido sustituidos en una sociedad que sólo prima el consumo, que sólo valora la riqueza.

4.4.4. Nunca llueve a gusto de todos: "La gente no siempre es de la misma opinión y es difícil que los acontecimientos agraden a todos por igual" (Carbonell Basset 2002: 280)

B: y pienso que tenemos quee- que ser también condescendientes con ellos [los inmigrantes]/// DESDE LUEGO/ NO ADMITIR/ a todo el mundo que entre// porque si admitimos a todo el que entra// los propios españoles nos vamos a tener que ir// yaa dee por sí tenemos el trabajo mal// pues si encima vienen de fuera y te lo cogen/ pero/// pero sí quee no sé/ pienso (chasquido) arreglarse no se va a arreglar nunca/ nunca porque nunca llu- llueve a gusto de todos/ que es lo que dicen/// ahí hay mucha política yy depende del partido que esté en el poder/ dirá que Sí// el otro dirá que NO// [...] (Gómez Molina 2005: 118 119). 
En cuanto al refrán Nunca llueve a gusto de todos, el interlocutor B, apoyándose en su fuerza ilocutiva de aseveración, de constatación de que la gente no tiene siempre la misma opinión y de que lo que ocurre no siempre agrada a todos, lo utiliza como argumento, como razón, de la idea que expone acerca de que "arreglarse no se va a arreglar nunca" conflictos con los inmigrantes-. De ahí que el refrán forme parte de una oración subordinada causal, introducida por la conjunción porque.

4.4.5. En todas partes cuecen habas, y en mi casa, a calderadas: "Advierte que las flaqueza humanas no son exclusivas de ningún país o lugar" y "Denota que en todas partes se hallan trabajos, y que cada uno tiene los suyos por mayores" (Campos y Barella 1996: 276)

A: ¿y te encuentras a gusto aquí?

B: me encuentro muy a gusto// han habido épocas de gente que a lo mejor han estado en tu entorno que no te has llevado TAL// pero bueno/ como ya la experiencia te indica que en todos los sitios se cuecen habas (entre risas)// pues entonces/ dices pues me quedo aquil/ me quedo aqui [...] (Gómez Molina 2005: 233).

El valor semiótico del refrán En todas partes cuecen habas y en mi casa, a calderadas es análogo al del primero. Va asimismo precedido de la conjunción adversativa pero más la interjección bueno, que designa resignación. De este modo, la fuerza ilocutiva de advertencia propia del refrán no va dirigida al otro interlocutor, sino que el emisor lo presenta como oposición a lo que él mismo dice en el fragmento anterior: "ha habido épocas de gente que a lo mejor han estado en tu entorno que no te has llevado" - debemos entender: que no te has llevado bien-, oposición que le sirve para aceptar resignadamente, de ahí la interjección bueno, que en todas partes encontrará personas con las que se llevará mal y, por supuesto, personas con las que se llevará bien. El refrán es, en consecuencia, el argumento que le permite concluir: "pues entonces/ dices pues me quedo aquil me quedo aqui"'.

4.4.6. El saber no ocupa lugar: "da a entender que nunca estorba el saber" (Fernández 1994: 231)

A: ¡caramba! mm/ muy bien cambiemos de tema ahora Vicente/ ee usted/ por ejemplo/ ¿qué opina?/ ¿todos los jóvenes/ han de ir a la universidad/ o han de estudiar formación profesional?/ o ¿qué opinión tiene sobre los estudios de la juventud?

$\mathrm{B}$ : bueno// ee estoo// yo creo que// el que valga para estudiar y tenga posibilidades/ debe de estudiar/ porque el saberr// ocupar lugar ¿eh?/ no ocupa lugar noo

A: (risas)

B: sí ocupa lugar $\boldsymbol{i e h ? / ~ p o r q u e e ~ e l ~ q u e ~ s a b e ~ p u e s ~ c o n c r e t a m e n t e ~ s i ~ t i e n e ~ e s t u d i o s / ~ s i e m p r e ~}$ entrará más pronto a trabajar enn- en una empresa/ la que sea/ equis/ a lo que se quiera dedicar esa persona/ quee el que no tenga estudios en realidad [...] (Gómez Molina 2005: 474).

El valor discursivo del último refrán, El saber no ocupa lugar, es semejante al del número 4). Aquí el refrán se ofrece también como argumento: va introducido por la conjunción porque, 
para justificar la opinión del interlocutor B acerca de que el que valga para estudiar y tenga posibilidades debe estudiar. Este valor discursivo concuerda bien con el tipo de acto de habla que le corresponde: desde la fuerza ilocutiva propia de una aseveración de autoría popular, el emisor razona sus ideas acerca de los estudios de los jóvenes.

5. Este análisis del valor discursivo de los refranes podría sumarse a un estudio sociolingüístico, puesto que el corpus del que han sido extraídos así lo permite, con el fin de averiguar posibles relaciones entre el uso de cada refrán y las características sociales del hablante que lo emite. Yo no lo he hecho. Sin embargo, sí quisiera dedicar el último punto del artículo a exponer unas reflexiones, más de orden sociológico que estrictamente sociolingüístico, las cuales, a mi parecer, darían cuenta, en parte, de la escasa presencia del refrán en la lengua hablada.

Es de sobra conocido que los refranes sobre el tiempo meteorológico constituyen un amplio conjunto dentro de refranero español. Por eso no deja de sorprender que, en el mínimo paremiológico de Tarnovska (2005), sólo aparezcan 3 relativos a la climatología: En abril, aguas mil, Marzo airoso y abril lluvioso hacen a mayo florido y hermoso y Hasta el cuarenta de mayo no te quites el sayo. De entre los incluidos en los listados de disponibilidad paremiológica de los hablantes sólo estos merecieron formar parte del mínimo según los criterios manejados por esta investigadora. Pero no debemos extrañarnos. En una época en que las informaciones sobre la previsión del tiempo se ofrecen en todos los medios de comunicación y en que la técnica y la ciencia - estoy pensando en el Meteosat- permiten predicciones fiables a medio y a corto plazo, los hablantes no necesitamos conocer ni memorizar un acervo de sabiduría popular que en tiempos pasados era esencial por el tipo de vida rural y la economía agraria de las gentes. Más todavía. Los habitantes de la ciudad de Alcalá de Henares, por ejemplo, no pueden decir Por San Blas la cigüeña verás, y si no la vieres año de nieves. Las están viendo durante todo el año a las cigüeñas, $\mathrm{y}$, a lo mejor, el verlas explica que se esté sufriendo un período de sequía como en muchas otras zonas. Y con razón, si pensamos en las consecuencias del cambio climático actual. De esta manera, las transformaciones en el modo de vida, con más peso ahora de los modos urbanos, industriales y de servicios, así como los desajustes climáticos en relación con otros tiempos no tan lejanos, podrían ser un par de explicaciones sociológicas de la baja ocurrencia de algunos refranes.

Algo semejante se puede afirmar en relación con otros amplios conjuntos temáticos del refranero, en concreto, con los refranes que hablan del vino y de las mujeres. Señala Manero Richard (2005: 98) que la responsabilidad ideológica del refrán compete a la comunidad lingüística, y en ella se escuda el hablante. Ahora bien, el hablante es también parte de esa comunidad y puede llegar a tomar conciencia de la carga ideológica del refrán si ésta se opone abiertamente a los presupuestos culturales existentes en el momento de su enunciación. Existe, pues, la posibilidad de que el locutor discrimine un refrán, lo bloquee desde el punto de vista pragmático, es decir, deje de utilizarlo. Estas ideas que Manero Richard enuncia de manera general tienen una buena aplicación a los refranes relativos al vino y a las mujeres. En una sociedad que dicta leyes contra el botellón y contra la violencia ejercida sobre las mujeres, en una sociedad en que de manera activa se pretende acabar con la discriminación de la mujer y lograr un estatus equiparable entre hombres y mujeres, no es políticamente correcto utilizar refranes que enaltezcan las borracheras o que denigren a las 
mujeres ${ }^{9}$. Estas circunstancias sociales podrían explicar que, en el mínimo paremiológico español, sólo aparezcan dos refranes sobre los bebedores, y los dos con la fuerza ilocutiva de simple constatación: Las penas con vino se ahogan y Los niños y los borrachos / locos nunca mienten. Refranes en que se mencione a las mujeres encontramos tres: Éramos pocos y parió la abuela, Tanto monta monta tanto (Isabel como Fernando) y Tiran más dos tetas que dos carretas. Si el segundo puede aplicarse a situaciones en que se quiera resaltar la igualdad entre hombres y mujeres, el primero, al comparar el aumento inoportuno de gente en un lugar donde ya hay mucha con el parto de una mujer vieja, resalta, con un cierto tono despectivo, las molestias y dificultades, es decir, lo negativo, en el parto de una mujer mayor. El último refrán mencionado, aun con la sinécdoque de la parte, tetas, por el todo, mujer, es vejatorio para las mujeres por evocar las imágenes de la mujer-objeto y de la mujer que subyuga al marido, cuando la realidad puede ser la inversa. Tenemos ahí otra posible explicación sociológica de la baja incidencia de estos grupos de refranes en el mínimo paremiológico y de su escaso uso por parte de los hablantes.

6. Hemos visto, pues, que el refrán puede y debe ser abordado desde múltiples perspectivas: lingüística, y especialmente textual, aplicada a la enseñanza de lenguas, sociológica, cultural, etc. etc. En este sentido, confío en que las ideas expuestas sirvan, al menos, para despertar el interés de futuros investigadores por las paremias. Así, además, tal vez tengamos datos para dejar de hablar de la baja frecuencia de los refranes, lo que no deja de ser una especie de muerte de esta unidad fraseológica. O tal vez así empecemos a hablar de su vitalidad, si comprobamos que los no usados son sustituidos por unidades nuevas, creadas siguiendo los modelos de los refranes tradicionales y que merecen formar parte de unos repertorios paremiológicos que todavía no han sido actualizados, piénsese en ejemplos como Por el interés te quiero, Andrés, que no suele formar parte de las colecciones de refranes.

\section{Apéndice I}

Refranes para la enseñanza del español como lengua extranjera, según Campo Martínez (2001), incluidos en el mínimo parmiológico establecido por Tarnovska (2005) ${ }^{10}$ :

A buen entendedor pocas palabras bastan

A caballo regalado no le mires el diente

A Dios rogando y con el mazo dando

A falta de pan, buenas son tortas

A mal tiempo, buena cara

A perro flaco todo se le vuelven pulgas

A quien madruga, Dios le ayuda

A rey muerto, rey puesto

Agua que no has de beber, déjala correr Al pan pan $y$ al vino vino
Ande yo caliente y riase la gente

Año de nieves, año de bienes

Arrieros somos y en el camino nos encontraremos

Aunque la mona se vista de seda, mona se queda

Bueno, si breve, dos veces bueno

Cada loco con su tema (y cada llaga con su postema)

Cada oveja con su pareja

9 Y eso que hay refranes misóginos, aspecto este de los refranes que ya ha sido analizado, véase, por ejemplo, Calero Fernández (1999: 127-134).

10 He hecho caso omiso de las variaciones formales que un mismo refrán pueda presentar y los he registrado en la forma asignada por Tarnovska (2005). 
Contigo pan y cebolla

Cría cuervos y te sacarán los ojos

Cuando el río suena, agua (algo/piedras) lleva

Cuando las barbas de tu vecino veas pelar, pon las tuyas a remojar

De lo que se come se cría

De noche todos los gatos son pardos

De tal palo tal astilla

Del dicho al hecho hay un gran / mucho trecho

Dime con quién andas y te diré quién eres

Dime de qué presumes y te diré de qué careces

Dios aprieta, pero no ahoga

Dos que duermen en el mismo colchón, se vuelven de la misma condición

El hombre y el oso, cuanto más feo, más hermoso

El que avisa no es traidor

El que no Ilora, no mama

El que se pica, ajos come

El que tiene boca se equivoca

En abril, aguas mil

En boca cerrada no entran moscas

En casa de herrero, cuchillo de palo

Hasta el cuarenta de mayo no te quites el sayo

Haz el bien y no mires a quién

Hombre prevenido / precavido vale por dos

Las cosas claras, y el chocolate espeso

Lo que no mata, engorda

Mal de muchos, consuelo de tontos

Marzo airoso y abril lluvioso hacen a mayo florido y hermoso
Más sabe el diablo por viejo que por diablo

Más vale malo conocido que bueno por conocer

Más vale pájaro en mano que ciento volando

Más vale prevenir que curar

Más vale solo que mal acompañado

Más vale tarde que nunca

Más vale una imagen que mil palabras

Nadie diga de esta agua no beberé

No dejes para mañana lo que puedas hacer hoy

No es oro todo lo que reluce

No hay mal que por bien no venga

No por mucho madrugar amanece más temprano

Ojo por ojo, diente por diente

Ojos que no ven, corazón que no siente

Perro ladrador, poco mordedor

Querer es poder

Quien a buen árbol se arrima, buena sombra le cobija

Quien bien te quiere te hará llorar

Quien calla, otorga

Quien mal anda, mal acaba

Quien mucho abarca, poco aprieta

Quien siembra vientos, recoge tempestades

Sobre gustos no hay nada escrito

Tanto tienes, tanto vales

Tanto va el cántaro a la fuente que acaba por romperse

Vísteme despacio que tengo prisa

\section{Apéndice II \\ Refranes del español hablado de Valencia:}

(1) A falta de pan, buenas son tortas: "Refrán irónico que aconseja conformarse con lo que se tiene o alcanza, a falta de otra cosa mejor" (Campos y Barella 1996: 155)

A: háblanos sobree tus diversiones/tus aficiones/ ¿cómo pasas el tiempo libre?

B: pues el tiempo libree/me gusta ocuparloo/ ee/ pues saliendo de acampada/ libre/mejor que guiada/ pero bueno si no hay pan buenas son tortas///(2") $\mathrm{mm} /$ pues me gusta mucho// pasear/ [...] (Gómez Molina 2001: 184-185).

(2) A lo hecho pecho: "Aconseja tener fortaleza para arrostrar las consecuencias de una desgracia o de un error que ya son irremediables" (Campos y Barella 1996: 278)

A: ¿sí?// hombre los japoneses están en esa línea también de disciplinaa/ y de trabajoo/ etcétera etcétera/ los chinos no tanto pero bueno/// ¿quée te hubiese gustado hacer que no hayas hecho/ o qué hubieses cambiado de tu vida? 
B: creo que eso ess algoo quee/ a lo hecho pecho/// noo- no ha lugar

A: ee/ ¿piensas alguna vez en tu jubilación? [...] (Gómez Molina 2001: 205).

(3) Tanto tienes, tanto vales: "Significa que el poder y la estimación entre los hombres suelen ser a proporción de la riqueza que tienen" (Campos y Barella 1996: 342)

A: ¿quée cambio de valores destacaría usted de aquella época a ésta?

B: totales/totales/ ee es decir/ la jerarquía- el esquema de valores ha sido trastocado completamente/// ee por unn consumismo atroz// ee por una ley/ dee tanto tienes tanto vales/ este- esta ley siempre ha existido/ lo que pasa que ha coexistido/ con otra serie de valores// sobre todo en las clases humildes// se primaba mucho el amor a la cultura [...] (Gómez Molina 2001: 339).

(4) Nunca llueve a gusto de todos: "La gente no siempre es de la misma opinión y es difícil que los acontecimientos agraden a todos por igual" (Carbonell Basset 2002: 280)

B: y pienso que tenemos quee- que ser también condescendientes con ellos [los inmigrantes]// DESDE LUEGO/ NO ADMITIR/ a todo el mundo que entre// porque si admitimos a todo el que entra// los propios españoles nos vamos a tener que ir// yaa dee por sí tenemos el trabajo mal// pues si encima vienen de fuera y te lo cogen/ pero/// pero sí quee no sé/ pienso (chasquido) arreglarse no se va a arreglar nunca/ nunca porque nunca llu- llueve a gusto de todos/ que es lo que dicen// ahí hay mucha política yy depende del partido que esté en el poder/ dirá que Sí// el otro dirá que NO// [...] (Gómez Molina 2005: 118-119).

(5) En todas partes cuecen habas, y en mi casa, a calderadas"!: "Advierte que las flaqueza humanas no son exclusivas de ningún país o lugar" y "Denota que en todas partes se hallan trabajos, y que cada uno tiene los suyos por mayores" (Campos y Barella 1996: 276)

A: ¿y te encuentras a gusto aqui?

B: me encuentro muy a gusto// han habido épocas de gente que a lo mejor han estado en tu entorno que no te has llevado TAL// pero bueno/ como ya la experiencia te indica que en todos los sitios se cuecen habas (entre risas)// pues entonces/ dices pues me quedo aqui/ me quedo aqui [...] (Gómez Molina 2005: 233).

(6) El saber no ocupa lugar: "da a entender que nunca estorba el saber" (Fernández 1994: 231)

A: jcaramba! $\mathrm{mm} /$ muy bien cambiemos de tema ahora Vicente/ ee usted/ por ejemplo/ ¿qué opina?/ ¿todos los jóvenes/ han de ir a la universidad/ o han de estudiar formación profesional?/ o ¿qué opinión tiene sobre los estudios de la juventud?

B: bueno// ee estoo// yo creo que// el que valga para estudiar y tenga posibilidades/ debe de estudiar/ porque el saberr// ocupar lugar ieh?/ no ocupa lugar noo

11 En el mínimo paremiológico de Tarnovska (2005. 217), este refrán aparece bajo la forma En todas partes se cuecen habas y en la mía, calderadas. La referencia del pronombre mía a la palabra partes no parece ser muy coherente. Es posible que haya algún error de trascripción del refrán, por eso la forma canónica que se ofrece es la que recogen Campos y Barella (1996: 276) en su diccionario. 


\begin{abstract}
A: (risas)
B: sí ocupa lugar ¿eh?/ porquee el que sabe pues concretamente si tiene estudios/siempre entrará más pronto a trabajar enn- en una empresa/ la que sea/ equis/ a lo que se quiera dedicar esa persona/ quee el que no tenga estudios en realidad [...] (Gómez Molina 2005: 474).
\end{abstract}

\title{
Referencias bibliográficas
}

Almela Pérez, R. y J. Sevilla Muñoz (2000): "Paremiología contrastiva: propuesta de análisis lingüístico", Revista de Investigación Lingüística, 1-III, págs. 7-47.

Briz, A. y Grupo Val.Es.Co (2002): Corpus de conversaciones coloquiales. Madrid, Arco/Libros. Calero Fernández, M Á. (1999): Sexismo lingüistico. Análisis y propuestas ante la discriminación sexual en el lenguaje. Madrid, Narcea.

Campo Martínez, $\mathrm{M}^{\mathrm{a}} \mathrm{A}$. del (2001): "Los refranes en la enseñanza de español como lengua extranjera", Revista de Estudios de Adquisición de la Lengua Española, 12, págs. 9-29.

Campos, J. G. y A. Barella (1996, $3^{\mathrm{a}}$ ed. revisada): Diccionario de refranes. Madrid, Espasa Calpe. Canellada, M. J. y B. Pallares (2001): Refranero español. Refranes, clasificación, significado y uso. Madrid, Castalia.

Carbonell Basset, D. (2002): Diccionario panhispánico de refranes. Barcelona, Herder. Casares, J. (1969, $1^{a}$ ed., reimp.[1950]): Introducción a la lexicografia moderna. Madrid, C.S.I.C. Čermák, F. (2005): "Introductores textuales en paremias y otras unidades fraseológicas". En Luque

Durán, J. de D. y A. Pamies Bertrán (eds.): La creatividad en el lenguaje: colocaciones idiomáticas y fraseología. Granada, Método Ediciones, págs. 235-255.

Combet, L. (1971): Recherches sur le "refranero" castillan. Paris, Société d'Édition "Les Belles Lettres".

Conca, M. (1987): Paremiologia. València, Servei de Publicacions de la Universitat de València. Corpas Pastor, G. (1996): Manual de fraseología española. Madrid, Gredos.

Corpas Pastor, G. (1998): "El uso de paremias en un corpus del español peninsular actual". En Wotjak, G. (ed.): Estudios de fraseologia y fraseografia del español actual. Frankfurt am Main/ Madrid, Vervuert / Iberoamericana, págs. 365-390.

Coseriu, E. (1966): "Structure lexicale et enseignement du vocabulaire". En Actes du Premier Colloque International de Linguistique Appliquée, organisé par la Faculté des Lettres et des Sciences Humaines de l'Université de Nancy, 26-23 octobre 1964. Nancy, Université de Nancy, págs. 175-252.

Díaz Pérez, J. C. (1997): "Desarrollo de la competencia paremiológica en estudiantes de enseñanza primaria y secundaria", Paremia, 6, págs. 190-194.

Fernández, M. (1994): Diccionario de refranes. Madrid, Alderabán.

García-Page Sánchez, M. (1997): "Propiedades lingüísticas del refrán (II): el léxico", Paremia, 6, págs. 275-280.

Gómez Molina, J. R. (coord.) (2001): El español hablado de Valencia. Materiales para su estudio. I. Nivel sociocultural alto. Valencia, Universitat de València.

Gómez Molina, J. R. (coord.) (2005): El español hablado de Valencia. Materiales para su estudio. II. Nivel sociocultural medio. Valencia, Universitat de València.

Hernando Cuadrado, L. A. (1997): "Estilística del refrán", Paremia, 6, págs. 327-332.

Laborda Gil, X. (2004): "Paremiología y refranes de la Casa de la Caritat de Barcelona, desde el punto de vista de la Pragmática", Lingüistica en la Red, II, 27 págs: http://www.linred.com (1005-2004).

Manero Richard, E. (2005): "Un caso especial de fenómeno polifónico de la lengua: el refrán". En Casado Velarde, M. et alii (eds.): Estudios sobre lo metalingüistico (en español). Frankfurt am Main, Peter Lang, págs. 93-115. 
Moreno Fernández, F., Cestero Mancera, A. Mª, Molina Martos, I. y F. Paredes García (2002): La lengua hablada en Alcalá de Henares. Corpus PRESEEA-ALCALA. I. Hablantes de instrucción superior. Alcalá de Henares, Servicio de Publicaciones de la Universidad de Alcalá.

Moreno Fernández, F., Cestero Mancera, A. Mª, Molina Martos, I. y F. Paredes García (2005): La lengua hablada en Alcalá de Henares. Corpus PRESEEA - ALCALÁ. II. Hablantes de instrucción media. Alcalá de Henares, Servicio de Publicaciones de la Universidad de Alcalá.

Moreno Fernández, F. y L. Florián Reyes (1999): "El proyecto DIES-RTVP (España). El lenguaje de la radio, la televisión y la prensa". En Garrido Medina, J. (ed.): La lengua y los medios de comunicación, I, Actas del Congreso Internacional Celebrado en la Universidad Complutense de Madrid en 1996. Madrid, Servicio de Publicaciones de la Universidad Complutense de Madrid, págs. 83-90. Olivera Soto, E. (1996): "Recursos estilísticos en el refranero", Paremia, 5, págs. 199-202.

Penadés Martínez, I. (2004): "¿Caracterizan las locuciones el registro coloquial?". En Villayandre Llamazares, M. (ed.): Actas del V Congreso de Lingüistica General, León, 5-8 de marzo de 2002, III. Madrid, Arco/Libros, págs. 2225-2235.

Seco, M., Andrés, O. y G. Ramos (1999): Diccionario del español actual. Madrid, Aguilar.

Seco, M., Andrés, O. y G. Ramos (2004): Diccionario fraseológico documentado del español actual. Locuciones y modismos españoles. Madrid, Aguilar.

Sevilla Muñoz, J. (1993): "Las paremias españolas: clasificación, definición y correspondencia francesa", Paremia, 2, págs. 15-20.

Sevilla Muñoz, J. y M ${ }^{a}$ T. Barbadillo de la Fuente (2005): "El máximo y el mínimo paremiológicos y sus implicaciones didácticas". En Luque Durán, J. de D. y A. Pamies Bertrán (eds.): La creatividad en el lenguaje: colocaciones idiomáticas y fraseologia. Granada, Método Ediciones, págs. 1-13.

Sevilla Muñoz, J. y J. Cantera Ortiz de Urbina (2002): Pocas palabras bastan. Vida e interculturalidad del refrán. Salamanca, Centro de Cultura Tradicional (Diputación de Salamanca).

Tarnovska, O. (2005): "El mínimo paremiológico en la lengua española". En Luque Durán, J. de D. y A. Pamies Bertrán (eds.): La creatividad en el lenguaje: colocaciones idiomáticas y fraseologia. Granada, Método Ediciones, págs. 197-217.

Tejero Robledo, E. (1997): "Paremiología geográfica en la Comunidad de Madrid. Su proyección didáctica en educación”, Paremia, 6, págs. 595-599. 